\title{
Predictive equation for basal metabolic rate of young Indian soldiers
}

\author{
L Robert Varte', Madhusudan Pal' \\ 'Scientist 'C', Department of Human Biology, Anthropology Group, Defence Institute of Physiology and Allied Sciences, \\ Defence Research and Development Organization, ${ }^{2}$ Scientist 'F', Department of Physiology, Ergonomics Division, \\ Defence Institute of Physiology and Allied Sciences, Defence Research and Development Organization, Delhi, India
}

Background: Currently, no specific predictive equation for BMR has been developed for the Indian armed forces whose BMR is expected to be higher compared to that of the general population because a greater proportion of their body weight is typically made up of muscle mass and bones as many studies show that the bones of active people are denser than those of sedentary people. Aims and Objective: The present study aimed to identify a best suitable BMR predictive equation specifically for the young Indian soldiers and to compare the measured BMR values with those estimated using other equations. Materials and Methods: Cross-sectional study on healthy individuals using random sampling. Anthropometric and body composition measurements, oxygen consumption (VO2) and carbon dioxide production (VCO2) during experiment were determined by the process of breath-bybreath gas analysis using K4b2 system. Data was analyzed using the Statistical Package for the Social Sciences version 12.0 (SPSS Inc, Chicago, IL, USA). The relationship between the measured BMR and the recorded variables were evaluated using Pearson's correlation coefficients and linear regression analysis. The results were considered significant at $5 \%$ level. Result: Mean measured BMR was significantly lower by $1.41 \%, 20.11 \%, 14.71 \%$, $19.21 \%$, and $21.8 \%$ ( $p<0.001$ ) compared to the mean BMR predicted using the Weir, FAO/WHO/UNU, ICMR, Miffin and Harris and Benedict predictive equations respectively. Conclusion: BMR in Indian soldier is lower than predicted by the FAO/WHO/UNU 1985 equations by an average of $20.1 \%$ suggesting that lower energy needs of present study with similar body weight may put them at greater risk for developing obesity, especially in overweight people.

Key words: Indian army, BMR, Prediction, Anthropometry, Body composition
http://nepjol.info/index.php/AJMS DOI: 10.3126/ajms.v7i6.14739 E-ISSN: 2091-0576 P-ISSN: 2467-9100

\section{INTRODUCTION}

Basal Metabolic Rate (BMR) is defined as the daily rate of energy metabolism that needs to be sustained by an individual in order to preserve the integrity of vital functions. ${ }^{1}$ It is used to gauge the physiological and biochemical integrity of the individual concerned. BMR measurement being a time-consuming exercise that requires special equipment thus is only suitable for small-scale studies. ${ }^{2}$ Hence, much attention has been paid to determining the accuracy of current BMR predictive equations, particularly in developing countries. ${ }^{3-7}$ Ideally,
BMR should be measured under conditions that are not influenced by external environmental factors such as ambient temperature, physical exertion and the effects of food or drugs. ${ }^{8}$ In 1948, the newly established FAO Standing Advisory Committee considered that 'the problem of assessing the calorie and nutrient requirements of human beings, with the greatest possible degree of accuracy, is of basic importance to FAO. ${ }^{9}$ Although reported equations derived from relatively large populations of healthy subjects may be useful, studies comparing measured BMR with BMR obtained by means of prediction equations in military populations are scarce. Currently, no 
specific predictive equation for BMR has been developed for the Indian armed forces.

Many studies show that the bones of active people are denser than those of sedentary people. ${ }^{10}$ The BMR of the Indian armed forces personnel is expected to be higher compared to that of the general population because a greater proportion of their body weight is typically made up of muscle mass and bones, as defence personnel are known to be more active than the general population.

Over prediction of BMR for Indians and those of the tropical living populations have been reported time and time again. ${ }^{1,3}$ In 1985 , the WHO proposed new equations in response to the impossibility of measuring BMR by direct calorimetry. These equations originated from a review of studies analyzed by Schofield, ${ }^{1}$ including approximately 11,000 BMR measurements taken using indirect calorimetry. However, several studies demonstrated that those equations overestimated BMR when used with different ethnic groups. ${ }^{11}$ Several other studies have revealed an overestimation of the BMR of Asians by $10 \%-11 \% \cdot{ }^{4-7,12}$ In one study undertaken on 58 men of a rural Indian population, the BMR values agreed well with values predicted by equations based on BMR measurements in Asian men of higher body weight, but were below values predicted by the new FAO/WHO/ UNU prediction equations by an average of 12.1 per cent. ${ }^{13}$

However, a contrasting result was reported in another study, the purpose of which was to establish whether international predictive equations overestimate the basal metabolic rate (BMR) of tropical populations. BMR was measured in healthy, physically active urban dwellers of low socioeconomic status (178 men and women aged 22-38 y) in Bangalore, Southern India. The BMR of both men and women, regardless of their nutritional status, was accurately estimated by age-and sex-specific FAO/WHO/ UNU equations. These findings suggest the absence of an enhanced metabolic response in weight-stable chronically undernourished adults. ${ }^{14}$

A number of formulas have been proposed to predict BMR using fundamental variables such as weight, height, gender and age. ${ }^{1}$ However, it has been reported that these predictive equations tend to produce unsystematic and incorrect results, which may vary from $70 \%$ to $140 \%$ when compared with measured energy consumption. ${ }^{2}$ The Schofield equations are commonly used to predict the BMR of populations living in temperate climates. However, it has been found that these equations produce questionable results when predicting the BMR of populations living in tropical climates. ${ }^{2}$

\section{AIMS AND OBJECTIVE}

The present study aimed to identify a best suitable BMR predictive equation specifically for the young Indian soldiers aged 18-25 years and to compare the measured $\mathrm{BMR}$ values with those estimated using the Weir, FAO/WHO/UNU, ICMR, Miffin and Harris and Benedict equations.

The present study also aimed to compare the BMR of Indian soldiers with other local and international measured BMR values.

\section{MATERIALS AND METHODS}

This cross-sectional study was conducted on young Indian soldiers aged 18-25 years on 29 healthy individuals and following parameters were studied: age, height, weight, BMI, $\mathrm{VO}_{2}$ and $\mathrm{VCO}_{2}$. Mean BMR calculated from values of $\mathrm{O} 2$ consumption and $\mathrm{CO} 2$ productions was $1349.13 \mathrm{kcal} /$ day among the males in the present study. The study utilized random sampling. Approval for the study was obtained from the Defence Research and Development Organization (DRDO), Ministry of Defence, India. All participants were within the normal body weight range, based on a body mass index (BMI) of $18.5-24.7 \mathrm{~kg} / \mathrm{m}^{2}$, and were healthy at the time of measurement. The participants provided written, informed consent prior to their involvement in the study. All experiments were conducted in controlled environment of $22^{\circ} \mathrm{C}-25^{\circ} \mathrm{C}, 50-55 \%$ relative humidity and at the same hour of the day between $0630 \mathrm{AM}$ and $0730 \mathrm{AM}$ prior breakfast every morning.

Anthropometric and body composition measurements were taken and body weight, measured in light clothing and barefoot to the nearest $0.1 \mathrm{~kg}$ and height, without shoes, were measured to the nearest $0.1 \mathrm{~cm}$ using the SECA 767 electronic personal scale (Medical Scales and Measuring Systems, Germany). BMI was calculated using the weight and height $\left(\mathrm{kg} / \mathrm{m}^{2}\right)$ data. In order to obtain an accurate data set, the trainees were briefed on the experimental protocol, which included fasting for 12-14 hours, not conducting any heavy physical activity the previous day, and ensuring they were in normal hydration status.

Oxygen consumption (VO2) and carbon dioxide production (VCO2) of each of the individual in supine position during experiment were determined by the process of breath-by-breath gas analysis using K4b2 system (K4b2, Cosmed S.r.l, Italy). BMR was calculated from measured oxygen consumption values in the present study. Before the experiment, every day the K4b2 system was calibrated with room air and standard gas mixture $(16 \% \mathrm{O} 2$ and $5 \% \mathrm{CO} 2)$. Portable unit and battery of the K4b2 system were fixed 
on the chest and back of the individual, respectively, with a harness. A flexible face mask that covered the subject's mouth and nose was secured to participants with a nylon mesh hairnet and velcro straps. The face mask contains flow meter and connects to the portable unit via capillary tube. After fitting the K4b2 system with the subjects both the data logger and telemetry mode of the system were put on. The subjects were then asked to breathe normally through the face mask for about 15 min supine position for the recording of resting $\mathrm{VO} 2$ and $\mathrm{VCO} 2$ parameters.

In addition, BMR was predicted using the equations formulated by Weir, FAO/WHO/UNU, ICMR, Miffin and Harris and Benedict for 18-29 years age group males.

The participants rested quietly in the supine position for 10 minutes prior to BMR measurement, which took approximately 30 minutes to complete the experiment. The recorded data was analyzed using the Statistical Package for the Social Sciences version 12.0 (SPSS Inc, Chicago, IL, USA). The results were expressed as the mean and standard deviation. The relationship between the measured BMR and the recorded variables, such as age, weight, height, VO2, VCO2, were evaluated using Pearson's correlation coefficients and linear regression analysis. The best subset was used to develop the predictive equations for BMR. The results were considered significant at 5\% level.

\section{RESULT}

The physical characteristics of the 29 young Indian soldiers are shown in Table 1. Mean $\pm \mathrm{SD}$ showed normal BMI range and $\mathrm{VO}_{2}(\mathrm{ml} / \mathrm{min})$ value of $191.01 \pm 26.48$ and $\mathrm{VCO}_{2}$ $(\mathrm{ml} / \mathrm{min} / \mathrm{kg})$ value of $177.75 \pm 27.51$.

Basal metabolic rates of the human subjects in $\mathrm{Kcal} / \mathrm{day}$, $\mathrm{MJ} /$ day and $\mathrm{Kcal} / \mathrm{kg} /$ day are shown in Table 2 with a mean \pm SD value of $1349.13 \pm 185.73,8.13 \pm 1.12$ and $21.30 \pm 2.65$, respectively.

The $\mathrm{O}_{2}$ consumption and $\mathrm{CO}_{2}$ production results measured by indirect calorimetry are listed in detail in Table 4.

In comparison to predicted values using Weir, FAO/ WHO/UNU, ICMR, Miffin and Harris and Benedict predictive equations, the BMR of the study participants were $1.41 \%, 20.11 \%, 14.71 \%, 19.21 \%, 21.88 \%$ lower than the Weir, FAO/WHO/UNU, ICMR, Miffin and Harris and Benedict predictive equations, respectively.

Predicted BMR was also compared with measured BMR. In order to validate the accuracy of the Weir, FAO/ WHO/UNU, ICMR, Miffin and Harris and Benedict, for 18-29 years age group males in estimating the BMR of our study population, the BMR values predicted using these equations were compared with the measured BMR (Table 3). The mean measured BMR was significantly lower by $1.41 \%$, $20.11 \%, 14.71 \%, 19.21 \%$, and $21.8 \%(\mathrm{p}<0.001)$ compared to the mean BMR predicted using the Weir, FAO/WHO/ UNU, ICMR, Miffin and Harris and Benedict predictive equations respectively. ${ }^{9,15-18}$ Linear regression equations of the BMR of the Indian Army recruits with their body weight were obtained for the 18-29 year age group.

In comparison with the measured value, the predicted value of $1351.86 \mathrm{Kcal} /$ day is only about $1.5 \%$ lower than that measured value of $1349.13 \mathrm{Kcal} /$ day, well within the $5 \%$ value acceptable.

The regression equation derived for the BMR $(R=0.495$, standard error of mean $=0.69)$ of Indian Army recruitees was as follows: $\mathrm{BMR}=1.647+0.063(\mathrm{~W})$, where BMR is expressed in $\mathrm{MJ} /$ day and $\mathrm{W}=$ body weight (in $\mathrm{kg}$ ).

Figure 1 presents the relationship between BMR and body weight. The linear regression equation of BMR on

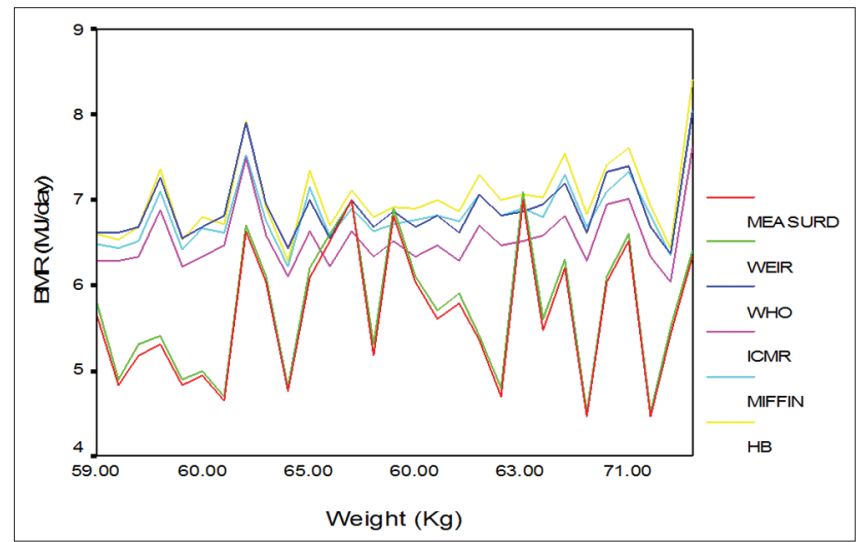

Figure I: Comparison between measured BMR and BMR predicted by the Weir, FAO/WHO/UN, ICMR, Miffin and Harris and Benedict equations

Table 1: Physical characteristics and body composition

\begin{tabular}{|c|c|c|c|c|c|c|}
\hline \multicolumn{4}{|c|}{ Participants } & \multicolumn{3}{|c|}{ Mean $\pm S D$ (range) } \\
\hline & Age (years) & Weight (kg) & Height (m) & BMI (kg/mt $\left.{ }^{2}\right)$ & VO2 (ml/min) & VCO2 $(\mathrm{ml} / \mathrm{min} / \mathrm{kg})$ \\
\hline$n=29$ & $\begin{array}{l}20.14 \pm 2.9 \\
(17.24-23.04)\end{array}$ & $\begin{array}{l}63.34 \pm 6.1 \\
(57.24-69.44)\end{array}$ & $\begin{array}{l}1.75 \pm 0.5 \\
(1.25-2.25)\end{array}$ & $\begin{array}{l}20.57 \pm 1.4 \\
(19.17-21.27)\end{array}$ & $\begin{array}{l}191.01 \pm 26.48 \\
(164.53-217.49)\end{array}$ & $\begin{array}{l}177.75 \pm 27.51 \\
(150.24-205.26)\end{array}$ \\
\hline
\end{tabular}


body weight derived from this study was compared with the equations recommended by Weir, FAO/WHO/UNU, ICMR, Miffin and Harris and Benedict predictive equations for the 18-29 year age group., ${ }^{95-18}$ Our study found that the Weir, FAO/WHO/UNU, ICMR, Miffin and Harris and Benedict predictive equations all overestimated the BMR of the Indian armed forces personnel.

\section{DISCUSSION}

The mean measured BMR of the recruits in the present study was $5.64 \pm 0.78 \mathrm{MJ} /$ day. A comparison of the measured BMR of the present study with other populations is shown in Table 5. The measured BMR found was higher than those other studies undertaken on Indian populations by Ismail, McNeill and Ferro Luzzi respectively. ${ }^{7,13,14}$ The measured BMR was similar to those of the Malaysian Armed Forces ${ }^{19}$ and lower than the UK study population. ${ }^{20}$

Earlier studies have highlighted the overestimation of BMR in many communities ${ }^{37,8,12}$ using the Schofield equation ${ }^{1}$ which was adopted in the FAO/WHO/UNU study, ${ }^{21}$ especially when the study populations were different from those included in the original data set. ${ }^{22}$ The mean measured BMR when compared to that predicted by the $\mathrm{FAO} / \mathrm{WHO} /$ UNU 1985 equations was lower by as much as $20.1 \%$, (p $<0.001$ ) which confirm the findings of earlier studies, which reported that the BMR was lower in the tropics than in temperate climates. ${ }^{1,3}$ It has been reported that Asian populations living in the tropics have lower basal metabolism compared to BMR predicted from body weight. ${ }^{3}$

The present study found significantly lower BMRs than predicted by Weir, FAO/WHO/UNU, ICMR, Mifflin and Harris and Benedict predictive equations. The predictive power of body weight, height and a combination of body weight and height, body weight and age, a combination of weight, height and age for BMR were studied. The results show that between body weight, height and age, weight was the best single predictor for BMR, followed by height and age. A regression equation with body weight as the independent variable yielded an $\mathrm{R}$ value of 0.495 . Regression equations of BMR with body weight and a combination of body weight and height as the independent variable yielded the same predicted power $(\mathrm{R}$ value $=0.495)$. Since body weight has been found to be the most suitable variable for the prediction of $\mathrm{BMR},{ }^{1,3,21}$ the BMR regression equation in the present study was developed using body weight as the only independent variable.

BMR is defined as the daily rate of energy metabolism that needs to be sustained by an individual in order to preserve

\begin{tabular}{lccc} 
Table 2: Basal metabolic rate (BMR) of subjects \\
\hline Participants & \multicolumn{3}{c}{ Mean BMR \pm SD (range) } \\
\cline { 2 - 4 } & Kcal/day & MJ/day & Kcal/kg/day \\
\hline Present study & $1349.13 \pm 185.73$ & $8.13 \pm 1.12$ & $21.30 \pm 2.65$ \\
& $(1163.40-1534.86)$ & $(7.01-9.25)$ & $(18.65-23.95)$ \\
\hline SD: Standard deviation, BMR: Basal metabolic rate
\end{tabular}

\begin{tabular}{|c|c|c|c|}
\hline Participants & $\begin{array}{l}\text { Predicted } \\
\text { equation }\end{array}$ & $\begin{array}{c}\text { Mean } \\
\text { BMR } \pm S D \\
\text { (MJ/day) }\end{array}$ & $\begin{array}{c}\text { Difference } \\
(\%)\end{array}$ \\
\hline Present study & & $5.64 \pm 0.78$ & - \\
\hline Weir & $\begin{array}{l}\mathrm{BMR}=0.063(\mathrm{~W}) \\
+1.754 \mathrm{MJ} / \text { day }\end{array}$ & $5.72 \pm 0.78^{*}$ & 1.41 \\
\hline FAO/WHO/UNU & $\begin{array}{l}\mathrm{BMR}=0.064(\mathrm{~W}) \\
+2.833 \mathrm{MJ} / \text { day }\end{array}$ & $6.90 \pm 0.39^{*}$ & 20.1 \\
\hline ICMR & $\begin{array}{l}\mathrm{BMR}=0.060(\mathrm{~W}) \\
+2.713 \mathrm{MJ} / \text { day }\end{array}$ & $6.54 \pm 0.37^{*}$ & 14.7 \\
\hline Mifflin & $\begin{array}{l}\mathrm{BMR}=0.059(\mathrm{~W}) \\
+3.077 \mathrm{MJ} / \text { day }\end{array}$ & $6.84 \pm 0.38^{*}$ & 19.2 \\
\hline $\begin{array}{l}\text { Harris and } \\
\text { Benedict }\end{array}$ & $\begin{array}{l}\mathrm{BMR}=00.072(\mathrm{~W}) \\
+2.445 \mathrm{MJ} / \text { day }\end{array}$ & $7.02 \pm 0.46^{*}$ & 21.8 \\
\hline
\end{tabular}

*Significantly different between measured BMR and predicted BMR equation at $\mathrm{p}<0.001, \mathrm{SD}$ : Standard deviation, BMR: Basal metabolic rate

\begin{tabular}{|c|c|}
\hline & Mean $\pm S D$ \\
\hline VO2 (I/min) & $0.191 \mathrm{l} / \mathrm{min} \pm 0.026$ \\
\hline VCO2 (1/min) & $0.178 \mathrm{l} / \mathrm{min} \pm 0.027$ \\
\hline Humidity (\%) & $50-55 \% \%$ \\
\hline Temperature $\left({ }^{\circ} \mathrm{C}\right)$ & $22^{\circ} \mathrm{C}-25^{\circ} \mathrm{C}$ \\
\hline Body mass (kg) & $63.34 \pm 6.18$ \\
\hline
\end{tabular}

the integrity of vital functions. ${ }^{1}$ It is used to gauge the physiological and biochemical integrity of the individual concerned. Ideally, it should be measured under conditions that are not influenced by external environmental factors such as ambient temperature, physical exertion and the effects of food or drugs. ${ }^{8}$

The prediction of BMR has attracted attention since the publication of the Food and Agriculture Organization/ World Health Organization/United Nations University (FAO/WHO/UNU) Expert Consultation report in 1985, ${ }^{21}$ which adopted the principle of relying on estimates of energy expenditure rather than energy intake to estimate human energy requirements. BMR forms the basis of this factorial approach because it constitutes between $60 \%$ and $75 \%$ of the total daily energy expenditure. The energy expenditure of different age and gender groups are currently estimated as multiples of BMR. 


\begin{tabular}{|c|c|c|c|c|c|}
\hline \multirow[t]{2}{*}{ Participants } & \multirow[t]{2}{*}{ Age (years) } & \multirow[t]{2}{*}{ Body weight (Kg) } & \multicolumn{2}{|c|}{ BMR } & \multirow[t]{2}{*}{ Reference } \\
\hline & & & MJ/day & kJ/kg/day & \\
\hline$n=11$ UK & 21 & 56.2 & 6.51 & 116 & Henry et al. 1987 \\
\hline $\mathrm{n}=58$ India & 31 & 51.6 & 5.40 & 105 & Mc Neill et al. 1987 \\
\hline $\mathrm{n}=35$ India & 28 & 50.1 & 5.18 & 103 & Ferro Luzzi et al. 1997 \\
\hline $\mathrm{n}=35$ Malaysian army recruits & $18-23$ & 56.2 & 5.74 & 102 & Isa 1991 \\
\hline $\mathrm{n}=35$ Malaysian army field training camp & $27-37$ & 63.9 & 5.80 & 91 & Isa 1991 \\
\hline $\mathrm{n}=29$ Indian army & $18-28$ & 63.3 & 5.73 & 91 & Present study \\
\hline
\end{tabular}

Underestimation or overestimation of BMR could result in errors during the planning of population energy allowances and the calculation of the energy requirements of an individual.

Several other studies have revealed an overestimation of the BMR of Asians by 10\%-11\%. ${ }^{4-6,711}$ These finding suggest that, if using these equations, the lower energy needs of Indians with similar body weight may put them at greater risk for developing obesity, especially in overweight people.

We conducted our BMR measurements under carefully controlled conditions, with consideration of many factors. Studies of BMR after periods of therapeutic low-energy intake suggest that BMR changes in relation to metabolic adjustment. Furthermore, there is a direct correlation between BMI and bias of predictive equations. Thus, to minimize such bias, ${ }^{23}$ we selected subjects with BMI in the normal range.

However, our study was carried out over a short period of time, and on a small scale. Thus, our results may not apply to the whole Indian defence population. Further studies validating the BMR of Indian defence personnel on a large scale should be implemented.

\section{CONCLUSION}

In conclusion, the present study shows that BMR in Indian adults is lower than predicted by the Weir equation by an average of about $1.41 \%$ in (18-29 years) and by an average of 20.1\% as predicted by FAO/WHO/UNU 1985 equations. This means that the present predicted equation is more or less similar to the Weir equation value which is considered as the gold standard for estimating BMR.

These findings suggest that the lower energy needs of present study with similar body weight may put them at greater risk for developing obesity, especially in overweight people. Larger-scale studies should be conducted in Indian soldiers to determine which equations are appropriate for Indian defence population.

\section{List of abbreviations}

ANOVA: Analysis of Variance

BMI: Body Mass Index

BMR: Basal Metabolic Rate

BSA: Body Surface Area

FAO: Food and Agriculture Organization of the United Nations

ICMR: Indian Council of Medical Research

Kcal/day: Kilo calorie per day

$\mathrm{Kcal} / \mathrm{kg} /$ day: Kilo calorie per kilogram per day

$\mathrm{MJ} /$ day: Mega Joules per day

R: Ratio of $\mathrm{VCO} 2 / \mathrm{VO} 2$

VO2: Oxygen consumption

VCO2: Carbon Dioxide eliminated

VO2/kg: Oxygen consumption per kilogram

W: Weight

WHO: World Health Organization

\section{ACKNOWLEDGEMENTS}

The authors would like to thank the Army recruitees for their generous participation in the project.

\section{REFERENCES}

1. Schofield WN. Predicting basal metabolic rate, new standards and review of previous work. Human Nutrition: Clinical Nutrition 1985; 39 (Suppl 1):5-41.

2. Stewart CL, Goody $\mathrm{CM}$ and Branson R. Comparison of two systems of measuring energy expenditure. Journal of Parenteral and Enteral Nutrition 2005; 29:212-217.

3. Henry CJ and Rees DG. New predictive equations for the estimation of basal metabolic rate in tropical peoples. European Journal of Clinical Nutrition 1991; 45:177-185.

4. Piers LS and Shetty PS. Basal metabolic rates of Indian women. European Journal of Clinical Nutrition 1993;47:586-591.

5. Shetty PS, Henry CJ, Black AE and Prentice AM. Energy requirements of adults: an update on basal metabolic rates (BMRs) and physical activity levels (PALs). European Journal of Clinical Nutrition 1996; 50:S11-S23.

6. Soares MJ, Piers LS, O'Dea K and Shetty PS. No evidence for an ethnic influence on basal metabolism: an examination of data from India and Australia. British Journal of Nutrition 1998; 79:333-341.

7. Ismail MN, Ng KK, Chee SS, Roslee R and Zawiah H. Predictive equations for the estimation of BMR in Malaysian adults. 
Malaysian Journal of Nutrition 1998; 4:81-90.

8. Henry CJ. Basal metabolic rate studies in humans: measurement and development of new equations. Public Health Nutrition 2005; 8:1133-1152.

9. FAO. Calorie requirements. Report of the Committee on Calorie Requirements, FAO Nutritional Studies, no. 5, Washington, D.C. 1950.

10. Keller P, Vollaard NB, Gustafsson T, Gallagher IJ, Sundberg CJ, Rankinen $\mathrm{T}$, et al. A transcriptional map of the impact of endurance exercise training on skeletal muscle phenotype. Journal of Applied Physiology 2011; 110: 46-59.

11. Wahrlich $V$ and Anjos LA. Validation of predictive equations of basal metabolic rate of women living in Southern Brazil. Revista de Saúde Pública 2001; 35:39-45.

12. Soares MJ, Francis DG and Shetty PS. Predictive equations for basal metabolite rates of Indian males. European Journal of Clinical Nutrition 1993; 47:389-394.

13. McNeill G, Rivers JP, Payne PR, de Britto JJ and Abel R. Basal metabolic rate of Indian men: no evidence of metabolic adaptation to a low plane of nutrition. Human Nutrition: Clinical Nutrition 1987; 41(6):473-483.

14. Ferro-Luzzi A, Petracchi C, Kuriyan R and Kurpad AV. Basal metabolism of weight-stable chronically undernourished men and women: lack of metabolic adaptation and ethnic differences. American Journal of Clinical Nutrition 1997; (66), 1086-1093.

15. Weir JB. New methods for calculating metabolic rate with special reference to protein. Journal of Physiology 1949; 109:1-9.

16. Harris JA and Benedict FA. A Biometric Study of Basal Metabolism in Man. Carnegie Institute of Washington: Washington, DC. 1919.

17. ICMR. Report on Nutrient Requirements and Recommended Dietary Allowances for Indians. National Institute of Nutrition, Hyderabad. 1998.

18. Miffin MD, Jeor ST, Inaoka T, Hill LA, Scott BJ, Daugherty SA, et al. A new predictive equation for resting energy expenditure in healthy individuals. American Journal of Clinical Nutrition 1990; 51:241-247.

19. Isa M. Energy requirement studies among Malaysian Armed Forces personnel. Master of Science Thesis, Universiti Kebangsaan Malaysia, 1991.

20. Henry CJ, Piggott S and Emery B. Basal metabolic rate and dietinduced thermogenesis in Asians living in Britain. Oxford, UK. Human Nutrition. Clinical Nutrition 1987; 41(5):397-402.

21. FAO/WHO/UNU Expert Consultation. Energy and Protein Requirements. WHO Technical Report Series 724. Geneva: World Health Organization 1985; 1-206.

22. Horgan GW and Stubbs J. Predicting basal metabolic rate in the obese is difficult. European Journal of Clinical Nutrition 2003; 57:335-340.

23. Siervo $M$, Boschi $V$ and Falconi $C$. Which REE prediction equation should we use in normal-weight, overweight and obese women? Clinical Nutrition 2003; 22 (2):193-204.

\section{Authors Contribution:}

LRV and MSP - Participated in the conception of the study, data analysis, interpretation of the data, review of literature and writing of the paper. All authors participated in the revision of the manuscript and approved the version submitted for publication.

Source of Support: Nil, Conflict of Interest: None declared. 